\title{
Reliability of the Intraoral Records for programming the Condylar Inclination of the Semiadjustable Articulator
}

\author{
Suasti Mendoza Diego ${ }^{1}$, Del Valle Lovato Juan ${ }^{2}$
}

\begin{abstract}
Aim and objective: The purpose of the investigation was to determine the reliability of intraoral records for the programming of the condylar inclination of the semiadjustable articulator (SAA), performed by dentistry students at the Central University of Ecuador (UCE).

Materials and methods: The concordance study was of an observational type and was carried out in sixth- and seventh-semester students of the Faculty of Dentistry of the UCE in the period 2019 to 2020. It was applied to a sample made up of 60 students: divided into G1 ( $n=30$ ), sixth-semester students and G2 $(n=30)$, seventh-semester students. The students were given articulated plaster models in an SAA in order to program the condylar inclination based on intraoral records, comparing it with the condylar inclination obtained from a computed tomography (CT) scan by an expert, determining inter-rater reliability. A Fleiss' Kappa test was performed for this study, with a 95\% confidence level.

Results: The average condylar inclination of the left side measured by the groups of students was $28.68^{\circ} \pm 10.16^{\circ}$ and for the right side it was $27.85^{\circ} \pm 10.59^{\circ}$, while in $\mathrm{CT}$, it was $45^{\circ}$ on the left side and $35^{\circ}$ on the right side. The range of discrepancy of the groups with the CT values is $4.30^{\circ}$ to $19.11^{\circ}$, with a significant difference between the programmed condylar inclination of the SAA between the study groups $(p<0.05)$, with greater amount of success in G1 ( $40 \%$ of students programmed the condylar inclination perfectly) compared to G2 ( $31.67 \%$ of students did it perfectly).

Conclusion: When performing the Fleiss'Kappa test, the concordance of the condylar inclination in an SAA programmed by the students gave a result with a negative sign, which suggests that there is no concordance of the articulator data compared to the CT, verifying that the students are not trained in this practice.

Clinical significance: The clinical significance of this study lies in the fact that students must learn to better program the condylar inclination so that the treatments they carry out in the future are jointly and preserving all the normal anatomical factors related to the mouth and the TMJ, in order to do so. achieve more personalized treatments for each patient.

Keywords: Condylar inclination, Intraoral records, Protrusion record, Semiadjustable articulator.

The Journal of Contemporary Dental Practice (2021): 10.5005/jp-journals-10024-3109
\end{abstract}

\section{INTRODUCTION}

The goal of prosthodontic rehabilitation is to design and manufacture a prosthesis that is in harmony with the patient's stomatognathic system. An important parameter in oral rehabilitation is the condylar inclination, which is described as the route traversed by the condyle in relation to the articular eminence when the mandible moves protrusively or laterally from the centric relation. ${ }^{1,2}$

Various intraoral and extraoral methods have been used to record the trajectory of the condyle and adjust the articulator accordingly. Centric and eccentric relations of the mandible can be recorded through the intraoral or positional wax method, graphic recordings, functional recordings, and cephalometry. However, some studies have not found significant differences between intraoral recording methods and radiographic recording methods. ${ }^{3}$ Curtis carried out a study where he compared the protrusive configurations in a joint adjusted by a pantograph and the protrusive configurations recorded by two intraoral recording materials: the first one made of polyvinyl siloxane and the second one of laminated metallized wax, determining that the mean condylar inclination obtained with the pantograph was greater than that recorded by the other two materials, while the analysis of variance showed that the condylar inclination recorded by the wax was statistically lower than that obtained by the pantograph. ${ }^{4,5}$
${ }^{1}$ Faculty of Dentistry, Central University of Ecuador, Quito, Ecuador

${ }^{2}$ Department of Restorative Dentistry, School of Dentistry, Central University of Ecuador and Ortodoncia and Implantes Private Practice, Quito, Ecuador

Corresponding Author: Suasti Mendoza Diego, Faculty of Dentistry, Central University of Ecuador, Quito, Ecuador, Phone: +593987139485, e-mail: dies19mendoza@hotmail.com

How to cite this article: Diego SM, Juan DVL. Reliability of the Intraoral Records for programming the Condylar Inclination of the Semiadjustable Articulator. J Contemp Dent Pract 2021;22(6):624-629. Source of support: Nil

Conflict of interest: None

The execution of the programming of semiadjustable articulators (SAAs) requires two condylar adjustments: the condylar guide and the Bennet angle, which are obtained through intraoral records and the Hanau formula. ${ }^{6,7}$

Some previous studies have tried to determine the reliability and validity of the various systems and procedures for programming condylar inclination, and the axiographic-pantographic systems are considered the most reliable due to their continuous evolution and because they recently incorporated the latest advances in computers and electronics; however, they are expensive methods. ${ }^{8}$

(0) Jaypee Brothers Medical Publishers. 2021 Open Access This article is distributed under the terms of the Creative Commons Attribution 4.0 International License (https://creativecommons.org/licenses/by-nc/4.0/), which permits unrestricted use, distribution, and non-commercial reproduction in any medium, provided you give appropriate credit to the original author(s) and the source, provide a link to the Creative Commons license, and indicate if changes were made. The Creative Commons Public Domain Dedication waiver (http://creativecommons.org/publicdomain/zero/1.0/) applies to the data made available in this article, unless otherwise stated. 
The programming of the condylar inclination could vary between evaluators; therefore, the need to perform a concordance test arises to determine the reliability of this technique. In this way, it was proposed to determine the reliability of the intraoral records in the programming of the condylar inclination of the SAA, determining the inter-rater concordance in sixth-and seventh-semester students of the Faculty of Dentistry (FD) of the Central University of Ecuador (CUE) in the period 2019 to 2020. The research hypothesis was that the level of concordance among undergraduate students when programming the condylar inclination in a SAA through protrusive records was null or low.

\section{Materials and Methods}

The proposed research was approved by the Subcommittee on Research Ethics in Human Beings of the Central University of Ecuador (SEISH-UCE in Spanish). The sample was 60 students from the sixth and seventh semesters of the CUE FD, and it was divided into two groups: $\mathrm{G} 1,(n=30)$ sixth-semester students and $\mathrm{G} 2$, ( $n=30$ ) seventh-semester students, who signed the informed consent to participate in the study.

\section{Methodological Procedure Intraoral Record}

The selected patient was female, the occlusal relationship was recorded with a wax roll (Aluwax; Dental wax products), considering the Christensen phenomenon that takes into account the posterior separation space that occurs between the maxillary and mandibular arches when a protrusive movement has been done. ${ }^{9}$

In order to carry out the protrusive record, the mandible was located in an edge position, that is, edge to edge of the incisor. Therefore, the professional placed the index finger on the patient's vestibular surface of the upper incisor and instructed her to try to bite the flesh, which resulted in a movement in position from edge to edge of the incisor. ${ }^{9}$ At the end of the occlusive movement, the bite was checked by placing it on plaster models and trimming the vestibular excesses with wax (Figs 1 and 2).

\section{Computed Tomography}

The tomographic procedure was performed in the Oral Radiology Department of the CUE School of Dentistry, with an exposure factor

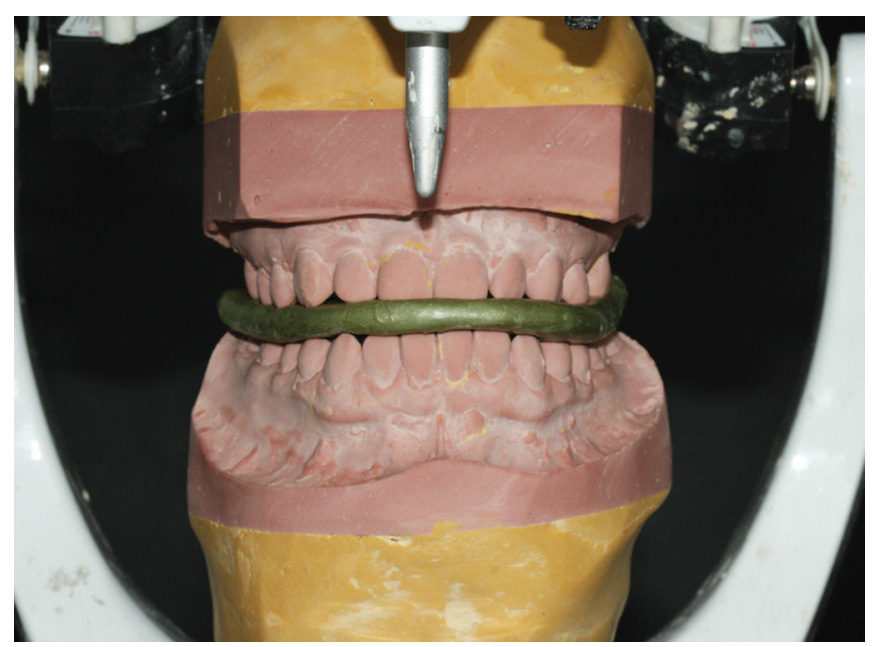

Fig. 1: Intraoral protrusive record with Aluwax Dental wax products (front view)

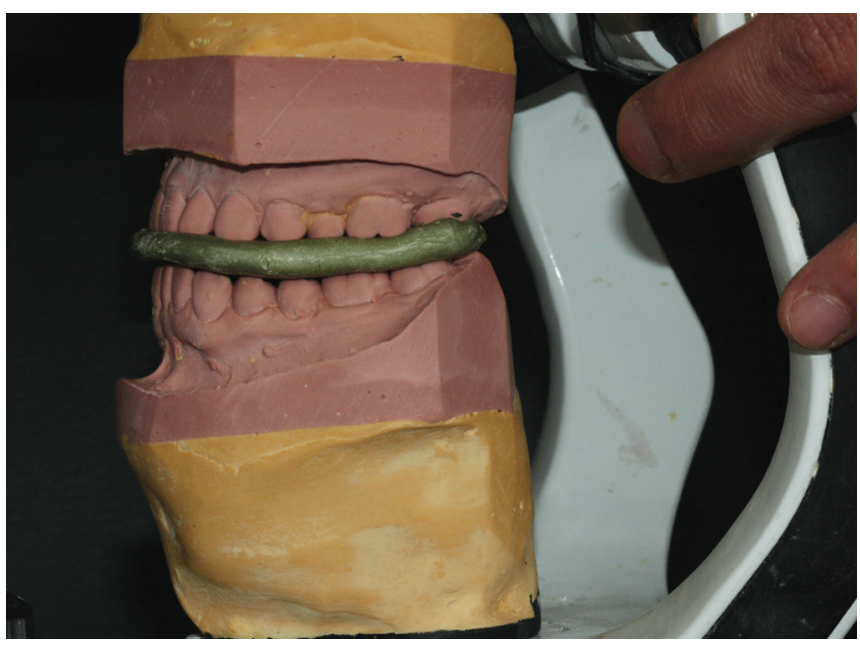

Fig. 2: Intraoral protrusive record with Aluwax Dental wax products (lateral left view)

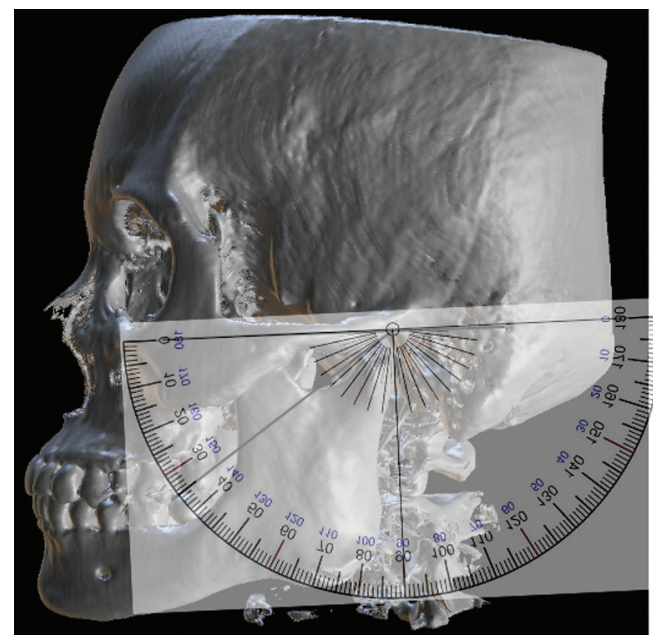

Fig. 3: Tomographic tracing left condylar inclination

of $68 \mathrm{kVp}$ and $10 \mathrm{~mA}$ at a $100 \%$ scale. In the research, a tracing of the sagittal contours of both articular eminences and the glenoid fossa was made, marking at the lowest point of the margin of the orbit called the "orbital" point, the highest point in the auditory meatus called the "porion," giving from the union of both points the horizontal plane of Frankfurt. They also identified the highest point in the articular eminence and the lowest point in the articular tubercle and constructed a second line to represent the mean inclination of the condylar path joining the two points, considering as a final value the result obtained from both examiners, reflected in a linear diagram of the panoramic tracing of the sagittal condylar guiding angle (Figs 3 and 4).

\section{Programming of the Semiadjustable Articulator by Students}

Once the impressions were obtained (Orthoprint; Zhermack), they were cast in plaster type IV (Elite rock; Zhermack), the upper model was articulated based on the face bow and the lower one by means of a $C R$ record and the students who decided to participate in the research, by signing the informed consent, were asked to program the condylar inclination based on the protrusive record, for which an explanation was provided on the points to consider 


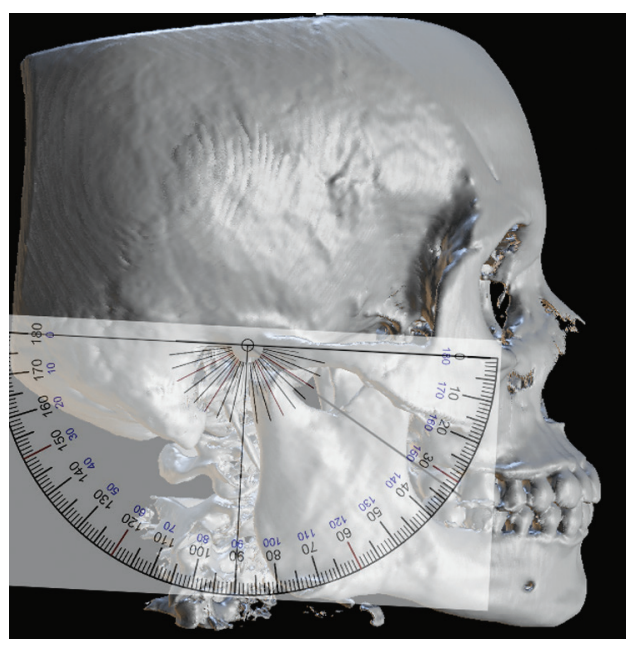

Fig. 4: Tomographic tracing right condylar inclination

for this procedure. Finally, the programming carried out by the student was compared with the actual inclination of the patient, recording the results on a data collection sheet specially designed for this research.

\section{Statistical Analysis}

The data resulting from the experimental procedure were entered into an Excel sheet and statistically analyzed using the SPSS statistical software program (release 9.0 for windows, SPSS, Chicago, Illinois) applying the Fleiss' Kappa and Student's t-test with a confidence level of $95 \%$.

\section{Results}

To determine the reliability of intraoral records in the programming of the condylar inclination of the SAA, determining the inter-rater concordance in sixth and seventh-semester students of the CUE FD in the 2019-2020 period, according to descriptive results, it was evidenced that the value of the condylar inclination of the left and right side tomography are $45^{\circ}$ and $35^{\circ}$, respectively. Meanwhile, the values of the condylar inclination obtained by the 60 students of sixth- and seventh-semester with the SAA on the left side presented a mean of $28.68^{\circ}$ and a standard deviation of $10.15^{\circ}$; and the right was $27.85^{\circ}$ and a standard deviation of $10.59^{\circ}$ (Table 1).

Fifty-three percent of the sixth-semester students calibrated the right side perfectly; however, only $26.67 \%$ calibrated the left side perfectly. Forty-three percent of the seventh-semester students calibrated the right side perfectly; however, only $20 \%$ calibrated the left side perfectly (Table 2).

When comparing the tomographic condylar inclination and the SAA of the left and right sides of the sixth and seventh semesters, it is evident that there is a significant variation, the value $p<0.05$ (Table 3).

In addition, the Student's $t$-test was applied for independent samples for the sixth and seventh semesters for the comparisons of the angle measurements of the left and right sides of the joint value where it was evidenced that statistically, the left side has reliability when checking that the $p$-value $(0.07)>0.05$. Meanwhile, on the right side, there is a significant variation, the $p$-value $(0.04)<0.05$. With the Levene test, it was evidenced that the $p$-value $>0.05$. The conclusion is that there is compatibility between the hypothesis of equality of half populations, where the

Table 1: Descriptive data of the condylar inclination in degrees obtained with SAA and CT of the left and right sides

\begin{tabular}{lcccrrrr}
\hline & & \multicolumn{3}{c}{$95 \%$ IC } & & \multicolumn{1}{c}{ Min } & Max \\
\cline { 3 - 5 } Condylar inclination data & Mean & Lower limit & Upper limit & \multicolumn{1}{c}{ D.E } & 45.00 & 45.00 \\
\hline Condylar inclination tomography LS & 45.000 & 45.00 & 45.00 & 0.00 & 35.00 & 35.00 \\
Condylar inclination tomography RS & 35.000 & 35.00 & 35.00 & 0.00 & 0.00 & 50.00 \\
Condylar articulator inclination LS & 28.683 & 26.06 & 31.31 & 10.16 & 10.00 & 60.00 \\
Condylar articulator inclination RD & 27.850 & 25.11 & 30.59 & 10.59 & -45.00 & 5.00 \\
Discrepancy LS (SAA-CT) & -16.317 & -18.94 & -13.69 & 10.16 & -25.00 & 25.00 \\
Discrepancy RS (SAA-CT) & -7.150 & -9.89 & -4.41 & 10.59 & & -25
\end{tabular}

RS, Right side; LS, Left side; SAA, Semiadjustable articulator; CT, Computed tomography; Cl, Confidence interval; S.D., Standard deviation; Min., Minimum; Max., Maximum

Table 2: Percentage distribution of variation of the condylar inclination (CT-SAA) of the left and right side $(n=60)$

\begin{tabular}{llrrl}
\hline Semester & Variation & RSn $(\%)$ & LS n (\%) & Total \\
\hline Sixth & Perfect $\left(<10^{\circ}\right)$ & $16(53.33)$ & $8(26.67)$ & $24(40.00 \%)$ \\
& Acceptable $\left(10^{\circ}-20^{\circ}\right)$ & $9(30.00)$ & $11(36.67)$ & $20(33.33 \%)$ \\
Seventh & Poor $\left(20^{\circ}-30^{\circ}\right)$ & $5(16.67)$ & $11(36.67)$ & $16(26.67 \%)$ \\
& Perfect $\left(<10^{\circ}\right)$ & $13(43.33)$ & $6(20.00)$ & $19(31.67 \%)$ \\
& Acceptable $\left(10^{\circ}-20^{\circ}\right)$ & $9(30.00)$ & $8(26.67)$ & $17(28.33 \%)$ \\
& Poor $\left(20^{\circ}-30^{\circ}\right)$ & $8(26.67)$ & $16(53.33)$ & $24(40.00 \%)$ \\
& Total & 60 & 60 & 120 \\
\hline
\end{tabular}

RS, Right side; LS, Left side; SAA, Semiadjustable articulator; CT, Computed tomography 
Table 3: Statistical Student's $t$ test

\begin{tabular}{|c|c|c|c|c|c|c|c|}
\hline \multirow[b]{2}{*}{ Condylar inclination difference } & \multirow[b]{2}{*}{ Mean } & \multirow[b]{2}{*}{ Dev. Deviation } & \multicolumn{2}{|c|}{$95 \% / C$} & \multirow[b]{2}{*}{$t$} & \multirow[b]{2}{*}{$d f$} & \multirow[b]{2}{*}{ Sig. (bilateral) } \\
\hline & & & Lower & Higher & & & \\
\hline $\begin{array}{l}\text { Difference of the condylar inclination } \\
\text { of the CT of the LS-SAA of the LS }\end{array}$ & 16.317 & 10.159 & 13.692 & 18.941 & 12.441 & 59 & 0.000 \\
\hline $\begin{array}{l}\text { Difference of the condylar inclination } \\
\text { of the CT of the - SAA of the RS }\end{array}$ & 7.150 & 10.60 & 4.413 & 9.887 & 5.227 & 59 & 0.000 \\
\hline
\end{tabular}

RS, Right side; LS, Left side; SAA, Semiadjustable articulator; CT, Computed tomography; Cl, Confidence interval; S.D., Standard deviation; Min., Minimum; Max., Maximum; df, degree of freedom; Sig., Significance or $p$ value.

Table 4: Comparison of the condylar inclination obtained by undergraduate students with SAA and the discrepancy, by semester

\begin{tabular}{|c|c|c|c|c|c|c|c|c|c|c|c|c|}
\hline \multirow{3}{*}{$\begin{array}{l}\text { Group statistics } \\
\text { Semester }\end{array}$} & & \multirow[b]{3}{*}{$N$} & \multirow[b]{3}{*}{ Mean } & \multirow[b]{3}{*}{ S.D. } & \multicolumn{2}{|c|}{ Levene's test } & \multicolumn{6}{|c|}{ prueba t para la igualdad de medias } \\
\hline & & & & & \multirow[b]{2}{*}{$F$} & \multirow[b]{2}{*}{$p$ value } & \multirow[b]{2}{*}{$t$} & \multirow[b]{2}{*}{$d f$} & \multirow[b]{2}{*}{$p$ value } & \multirow{2}{*}{$\begin{array}{l}\text { Difference } \\
\text { of means }\end{array}$} & \multicolumn{2}{|c|}{$95 \%$ IC } \\
\hline & & & & & & & & & & & Min. & Max. \\
\hline \multirow[t]{2}{*}{ Left articulator value } & Sixth & 30 & 31.03 & 9.69 & 0.20 & 0.66 & 1.83 & 58.00 & 0.07 & 4.70 & -0.45 & 9.85 \\
\hline & Seventh & 30 & 26.33 & 10.23 & & & 1.83 & 57.83 & 0.07 & 4.70 & -0.45 & 9.85 \\
\hline \multirow[t]{2}{*}{ Right articulator value } & Sixth & 30 & 30.70 & 10.92 & 0.11 & 0.74 & 2.15 & 58.00 & 0.04 & 5.70 & 0.38 & 11.02 \\
\hline & Seventh & 30 & 25.00 & 9.61 & & & 2.15 & 57.09 & 0.04 & 5.70 & 0.38 & 11.02 \\
\hline \multirow[t]{2}{*}{ Left discrepancy } & Sixth & 30 & -13.97 & 9.69 & 0.20 & 0.66 & 1.83 & 58.00 & 0.07 & 4.70 & -0.45 & 9.85 \\
\hline & Seventh & 30 & -18.67 & 10.23 & & & 1.83 & 57.83 & 0.07 & 4.70 & -0.45 & 9.85 \\
\hline \multirow[t]{2}{*}{ Right discrepancy } & Sixth & 30 & -4.30 & 10.92 & 0.11 & 0.74 & 2.15 & 58.00 & 0.04 & 5.70 & 0.38 & 11.02 \\
\hline & Seventh & 30 & -10.00 & 9.61 & & & 2.15 & 57.09 & 0.04 & 5.70 & 0.38 & 11.02 \\
\hline
\end{tabular}

RS, Right side; LS, Left side; SAA, Semiadjustable articulator; CT, Computed tomography; IC, Cl, Confidence interval; S.D., Standard deviation; Min., Minimum; Max., Maximum

Table 5: Fleiss' Kappa inter-rater concordance test

\begin{tabular}{lllllll}
\hline Condylar inclination CT vs SAA & Kappa & $\begin{array}{l}\text { Asymptotic } \\
\text { standard error }\end{array}$ & $Z$ & Z value & \multicolumn{2}{l}{$\begin{array}{l}\text { Cower 95\% asymptotic } \\
\text { Upper 95\% asymptotic } \\
\text { Cl bound }\end{array}$} \\
\hline LS sixth & -0.355 & 0.084 & -4.217 & 0.000 & -0.520 & -0.190 \\
RS sixth & -0.322 & 0.086 & -3.732 & 0.000 & -0.491 & -0.153 \\
LS seventh & -0.391 & 0.089 & -4.386 & 0.000 & -0.566 & -0.216 \\
RS seventh & -0.401 & 0.085 & -4.697 & 0.000 & -0.568 & -0.234 \\
LS total & -0.359 & 0.060 & -5.939 & 0.000 & -0.477 & -0.240 \\
RS total & -0.353 & 0.059 & -5.991 & 0.000 & -0.468 & -0.237 \\
\hline
\end{tabular}

RS, Right side; LS, Left side; SAA, Semiadjustable articulator; CT, Computed tomography; IC, Cl, Confidence interval; S.D., Standard deviation

values presented by sixth-semester students are not different from those of seventh-semester students, considering that they have equal variances (Table 4).

To determine the reliability of the intraoral recordings in the programming of the condylar inclination of the SAA, there was no agreement between the measurements of the CT and the SAA because the $p$-value was negative. (Table 5)

\section{Discussion}

In prosthodontic, it is of great importance to identify the condylar inclination, because the correct elaboration of the fixed or removable dental prosthesis depends on this parameter and it also maintains the patient's masticatory system in harmony, ${ }^{1}$ for this reason dentists must know and master the use of dental articulators, specifically the values of inclination of the condylar trajectory, Bennett's angle, which is obtained by means of protrusive or lateral registrations, ${ }^{10}$ to simulate the kinetics of the masticatory system, which allows customizing morphological and functional characteristics of the occlusion. Intraoral records are made using different materials, such as waxes, which are placed between the teeth and the patient is asked to perform both protrusive and lateral movements (if necessary) so that the incisal edges and occlusal surfaces are marked in the wax pattern, then they are transferred to the SAA and placed between the fixed models and in relation to the protrusion, we can know what the protruding movement of the patient was, thus establishing the condylar inclinations and subsequently securing the lock nuts to record the inclination value. ' Based on the above, the determination of the reliability of the intraoral records is based on the programming of the condylar inclination of the SAA, determining the inter-rater concordance in sixth- and seventh-semester students of the FD of the CUE in the period 2019 to 2020.

With the use of computerized tomography, the expert determined that the sagittal condylar guiding angle on the left side was $45^{\circ}$ and on the right side it was $35^{\circ}$. These values were used 
as a point of comparison with the programming reported by the sixth- and seventh-semester students of the FD of the UCE in the period 2019-2020, according to the literature that mentions that generally the left and right eminences rarely have exactly the same inclinations, contours, and slopes, given the fact that the degrees of the condylar angle vary between $22^{\circ}$ and $65^{\circ},{ }^{10}$ which agrees with the results of the present study.

Regarding the use of digital computed tomography (CT), it is a more precise method, demonstrating the greatest benefit for the patient by minimizing possible occlusal interferences during mandibular movements. ${ }^{11}$ However, these advanced images in some cases are not available, which is why students and dentists must master condylar angle measurement techniques based on intraoral recordings to calibrate the SAA.

In the data collection, it was reported that the average of the condylar inclination of the left side measured by the sixthsemester students was $31.03^{\circ}$ and those of the seventh semester was $25.89^{\circ}$, with respect to the right side the sixth semester was of $30.70^{\circ}$ and those of the seventh semester was $26.64^{\circ}$, with a range of discrepancy with the values of the CT from $4.30^{\circ}$ to $19.11^{\circ}$, where the measurements of the CT were greater than those registered by the sixth- and seventh-semester students, agreeing with the research of Shreshta et al. ${ }^{12}$ who demonstrated that the measurements obtained by CT were greater than that of the plaster cast and exhibited low levels of association between them. They also mention that the inconsistency of the intraoral methods may be due to the material used, sagittal condylar angle changes with the degree of protrusion and experience of the operator; additionally, the tomography images are not very accurate in some cases for the measurement of condylar inclination, due to the fact that there are intervening structures; in addition, the reading may vary depending on the type of device and the cross section used..$^{13}$ For this reason, it is recommended that general dentists and specialists do not ignore the use of clinical methods for programming the condylar inclination of the SAA. They argue that they are more economical, practical, and it is possible to use them in areas with little accessibility (rural areas).

The results agree with a previous study, ${ }^{14}$ who evaluated the influence of the operator, the type of articulator, and the programming of the articulator through the accuracy and precision of a wax record, showed that different operators can obtain different values of the condyle angle, representing significantly varied measurements, with values that ranged between $34^{\circ}$ and $57^{\circ}$. Therefore, the person who takes the measurement of the condylar angle to calibrate the SAA based on intraoral recordings is a factor that directly influences the precision and accuracy of the device.

However, the findings of the present investigation differ from those published by Hindle et al. ${ }^{15}$ who determined the use of articulators and the recommendations for various restorative procedures that undergraduate dental students from the United Kingdom had used a structured questionnaire with nine questions about the type of articulator recommended for each procedure, steps that must be followed for it, showing that the students fully knew the practices of each of the procedures and also that they had correctly interpreted the questions. One of the possible differences between both studies is the applied methodology, since the research by Hindle et al. obtained the theoretical knowledge of the dental students on the use of articulators; on the other hand, in the current study, it was considered the practical part on how to program the condylar inclination of the SAA based on intraoral records. ${ }^{15}$
Through the results of the present study, it was evidenced that there is no reliability of intraoral records for the programming of the condylar inclination of the SAA of the students of the sixth and seventh semesters of the FD of the CUE in the period 2019 to 2020. The values of inter-rater concordance of the Fleiss' Kappa test is negative; therefore, there is no concordance between the measurements of condylar inclination recorded by the students to program the SAA and those established by the specialist through computerized tomography, which was confirmed by the measurement of the intraoral record by the specialist. These findings show that sixth and seventh undergraduate students of the FD of the CUE are not trained to perform condylar programming, one of the factors that may be intervening is that teaching the theory of this technique begins in the sixth semester of the degree and it is possible that these students have the most up-to-date knowledge; in addition, the sixth-semester students showed more interest when the specialist taught them the method compared to the seventh-semester students.

\section{Conclusion}

The level of concordance between undergraduate students when programming the condylar inclination in an SAA through protrusive records was null with respect to that reported by the expert, due to the negative values of the Fleiss' Kappa test, verifying that the undergraduate students are not trained in the practice of calibrating the condylar inclination of a SAA.

Limitations of study: The limitations of the study revolve around the experience of the operator, in this case, as they are undergraduate students and do not have experience in the SAA program.

Future directions: The future directions of this study could be to evaluate graduate students or prosthodontics because they have expertise in programming the condylar inclination of the SAA.

\section{References}

1. Prasad D, Shah N, Hegde C. A clinico-radiographic analysis of sagittal condylar guidance determined by protrusive interocclusal registration and panoramic radiographic images in humans. Contemp Clin Dent 2012;3(4):383-387. DOI: 10.4103/0976-237X.107419. Available from: https://pubmed.ncbi.nlm.nih.gov/23633793/.

2. Shetty S, Kunta M, Shenoy, K. A clinico-radiographic study to compare and co-relate sagittal condylar guidance determined by intraoral gothic arch tracing method and panoramic radiograph in completely edentulous patients. J Indian Prosthodontic Soc Jan-Mar 2018;18(1):19-23.doi: 10.4103/jips.jips_207_17.Available from: https:// pubmed.ncbi.nlm.nih.gov/29430137/.

3. Ventura de la Torre J, Domínguez Cardoso P, Cañadas Rodríguez D, et al. Fiabilidad y validez de los diferentes sistemas de registros de la inclinación de la trayectoria condilar (ITC): Revisión bibliográfica. Av Odontoestomatol 2007;23(2):83-90. DOI: 10.4321/S021312852007000200004. Available from: https://scielo.isciii.es/pdf/ odonto/v23n2/original3.pdf.

4. Curtis DA. A comparison of protrusive interocclusal records to pantographic tracings. J Prosthet Dent 1989;62(2):154-156. DOI: 10.1016/0022-3913(89)90303-X. Available from: https://pubmed.ncbi. nlm.nih.gov/2668509/.

5. Tannamala P, Pulagam M, Pottem S, et al. Condylar guidance: correlation between protrusive interocclusal record and panoramic radiographic image: a pilot study. J Prosthodont 2012;21(3):181-184. DOI: 10.1111/j.1532-849X.2011.00811.x. Available from: https:// pubmed.ncbi.nlm.nih.gov/22339685/.

6. Bhawsar SV, Marathe AS, Ansari SA. Evaluation of Hanau's formula in determination of lateral condylar guidance: a clinical research study. 
J Indian Prosthodontic Soc 2015;15(4):326-330. DOI: 10.4103/09724052.161566. Available from: https://pubmed.ncbi.nlm.nih. gov/26929535/.

7. Javid N, Porter M. The importance of the Hanau formila in construction of complete dentures. J Prosthet Dent 1975;34(4):397-404. DOI: 10.1016/0022-3913(75)90156-0. Available from: https://pubmed.ncbi. nlm.nih.gov/1100807/.

8. Pesce Ortega MC, Barbano Maturana M, Saldivia Berríos J, et al. Comparación de la posición condilar entre dos técnicas de registro de relación céntrica mediante tomografía espiral. Rev Clin Periodoncia Implantol Rehabil Oral 2014;7(1):21-24. DOI: 10.4067/ S0719-01072014000100005. Available from: https://scielo.conicyt. cl/scielo.php?script=sci_arttext\&pid=S0719-01072014000100005.

9. AlonsoP,Albertini J,Bechelli A. Oclusióny Diagnósticoen Rehabilitación Oral [Internet]. Buenos Aires: Editorial Médica Panamericana Sa de; 1999. Available from: https://www.edicionesjournal.com/Papel/ 9789500600705/Oclusión+y+Diagnóstico+en+Rehabilitación+Oral.

10. Mawani D, Muddugangadhar B, Das A, et al. Comparative evaluation of condylar inclination in dentulous subjects as determined by two radiographic methods: orthopantomograph and cone-beam computed tomography - an in vivo study. J Indian Prosthodont Soc 2019;19(2):113-119. DOI: 10.4103/jips.jips_266_18. Available from: https://pubmed.ncbi.nlm.nih.gov/31040544/.
11. Galagali G, Kalekhan S, Nidawani P, et al. Comparative analysis of sagittal condylar guidance by protrusive interocclusal records with panoramic and lateral cephalogram radiographs in dentulous population: a clinico-radiographic study. J Indian Prosthodont Soc 2016;16(2):148-153. DOI: 10.4103/0972-4052.179322. Available from: https://pubmed.ncbi.nlm.nih.gov/27141164/.

12. Shrestha $P$, Jain V, Seith Bhalla A, et al. A comparative study to measure the condylar guidance by the radiographic and clinical methods. J Adv Prosthodont 2012;4(3):153-157. DOI: 10.4047/jap.2012.4.3.153. Available from: https://pubmed.ncbi.nlm.nih.gov/22977723/.

13. Kwon OK, Yang S, Kim JH. Correlation between sagittal condylar guidance angles obtained using radiographic and protrusive occlusal record methods. J Adv Prosthodont 2017;9(4):302-307. DOI: 10.4047/ jap.2017.9.4.302. Available from: https://pubmed.ncbi.nlm.nih. gov/28874998/.

14. Peraire M, Gomis JM, Cantarell JMA, et al. Factores que alteran la exactitud y precisión en la determinación del ángulo de la guía condílea mediante registros de cera con un articulador semiajustable. Rev Eur Odontoestomatol 2002;14(5):257-262. Available from: https:// core.ac.uk/download/pdf/43553638.pdf.

15. Hindle J, Craddock H. The use of articulators in UK dental schools. Eur J Dent Educ 2006;10(4):197-203. DOI: 10.1111/j.1600-0579.2006.00416.x. Available from: https://pubmed.ncbi.nlm.nih.gov/17038011/. 